\title{
Density Functional Theory Studies of the [2]Rotaxane Component of the Stoddart-Heath Molecular Switch
}

Yun Hee Jang, Sungu Hwang, Yong-Hoon Kim, Seung Soon Jang, and William A. Goddard, III* Materials and Process Simulation Center, Beckman Institute (139-74)

California Institute of Technology, Pasadena, California 91125

\section{Supporting Information}

\section{A. Detailed Figures}<smiles>CC1CC(=C2C[C@H](C)[C@H](C)C2)C[C@@H]1C</smiles>

(a)

TTF

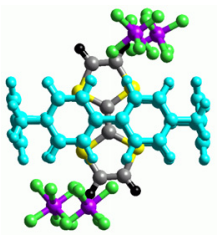

(b) $\quad($ TTF $)\left(C^{2} B P Q T\right)\left(P_{6}\right)_{4}$

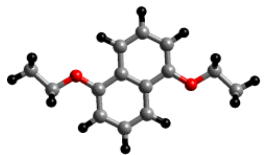

DNP

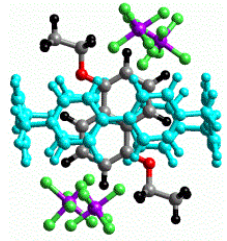

$(\mathrm{DNP})(\mathrm{CBPQT})\left(\mathrm{PF}_{6}\right)_{4}$

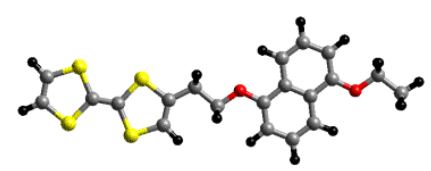

(c)

TTF-DNP

Figure S1. Simplified models of 1 employed in this study. Color code: yellow (S), red (O), gray (C), black (H), purple (P), light green (F), and light blue (CBPQT).
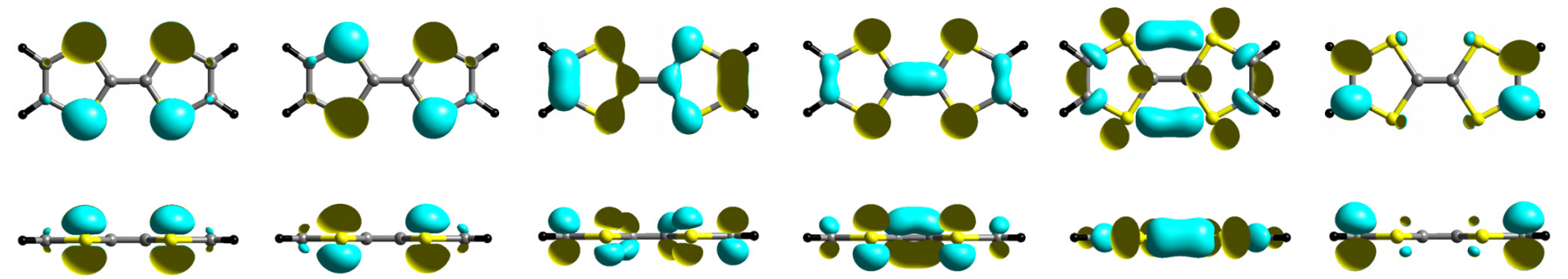

HOMO-3 $(\pi ;-7.88 \mathrm{eV})$ HOMO-2 $(\pi ;-7.55 \mathrm{eV})$ HOMO-1 $(\pi ;-6.40 \mathrm{eV})$ HOMO $(\pi ;-4.52 \mathrm{eV})$ LUMO $(\sigma ;-0.95 \mathrm{eV}) \quad$ LUMO+1 ( $\pi ;-0.11 \mathrm{eV})$

Figure S2. Frontier molecular orbitals of TTF (B3LYP/6-31G**). Essentially the same shapes are found with PBE/6-31G**. Color code: yellow (S), gray (C), and black $(\mathrm{H})$.
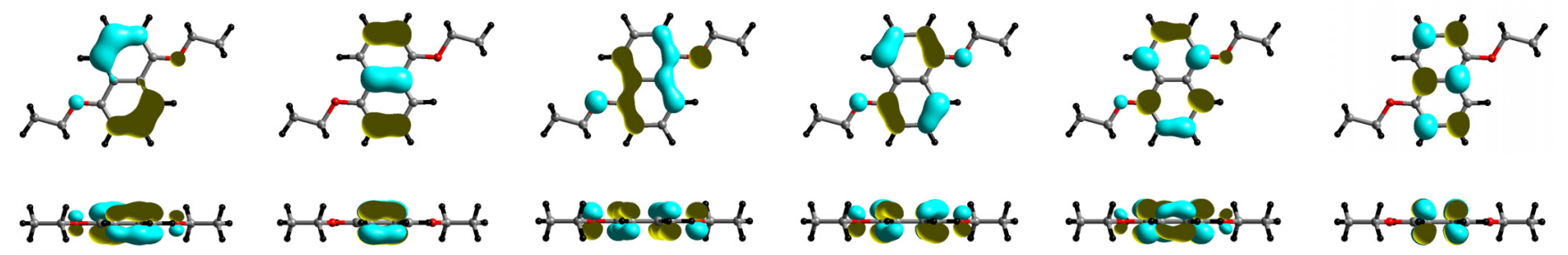

HOMO-3 $(\pi ;-8.28 \mathrm{eV})$ HOMO-2 $(\pi ;-6.39 \mathrm{eV})$ HOMO-1 $(\pi ;-6.30 \mathrm{eV})$ HOMO $(\pi ;-5.06 \mathrm{eV})$ LUMO $(\pi ;-0.43 \mathrm{eV}) \quad$ LUMO+1 $(\pi ; 0.02 \mathrm{eV})$

Figure S3. Frontier molecular orbitals of DNP (B3LYP/6-31G**). Essentially the same shapes are found with PBE/6-31G**. Color code: red (O), gray (C), and black $(\mathrm{H})$. 

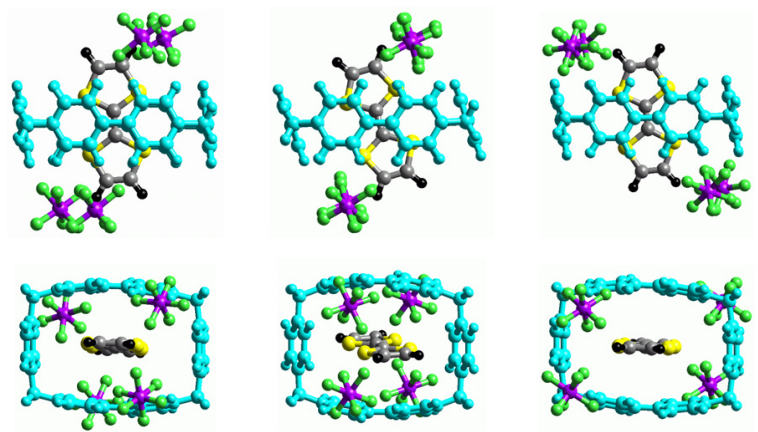

Configuration 1a $(0 \mathrm{kcal} / \mathrm{mol})$

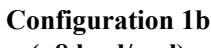

\section{Configuration 2} $(5 \mathrm{kcal} / \mathrm{mol})$
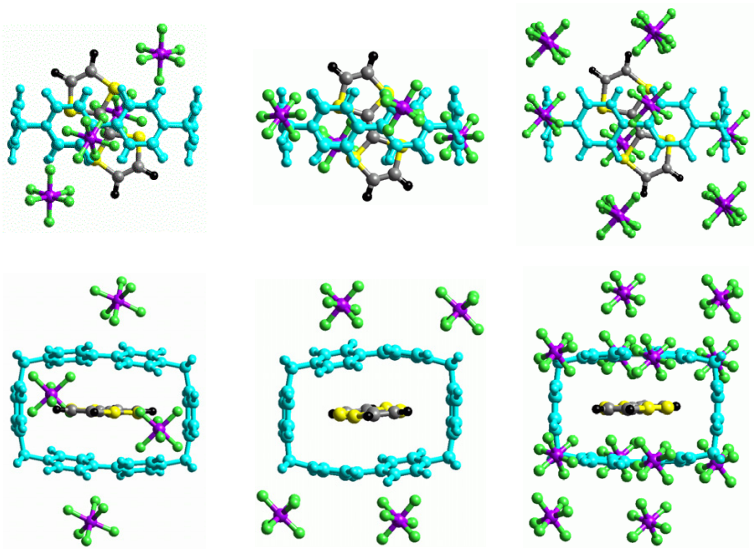

Configuration 3 $(28 \mathrm{kcal} / \mathrm{mol})$

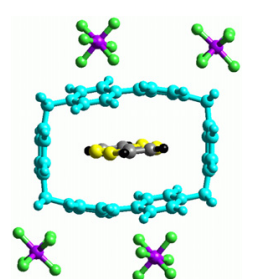

Configuration 4 $(58 \mathrm{kcal} / \mathrm{mol})$

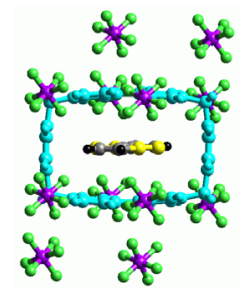

Crystal structure $(\mathrm{TTF})(\mathrm{CBPQT})\left(\mathrm{PF}_{6}\right)_{4}$

Figure S4. Side and top view of the optimized structures for (TTF)(CBPQT) $\left(\mathrm{PF}_{6}\right)_{4}$ with five different arrangements of the four $\mathrm{PF}_{6}{ }^{-}$'s around the $\mathrm{CBPQT}^{4+}$ ring. We find Configurations $\mathbf{1}$ and $\mathbf{2}$ to be the most favorable. Shown also is the arrangement of nearest-neighbor $\mathrm{PF}_{6}{ }^{-} \mathrm{s}$ around a CBPQT in the crystal structure of $(\mathrm{TTF})(\mathrm{CBPQT})\left(\mathrm{PF}_{6}\right)_{4} \cdot{ }^{23}$ Color code: yellow $(\mathrm{S})$, gray $(\mathrm{C})$, black $(\mathrm{H})$, purple $(\mathrm{P})$, light green $(\mathrm{F})$, and light blue (CBPQT). 

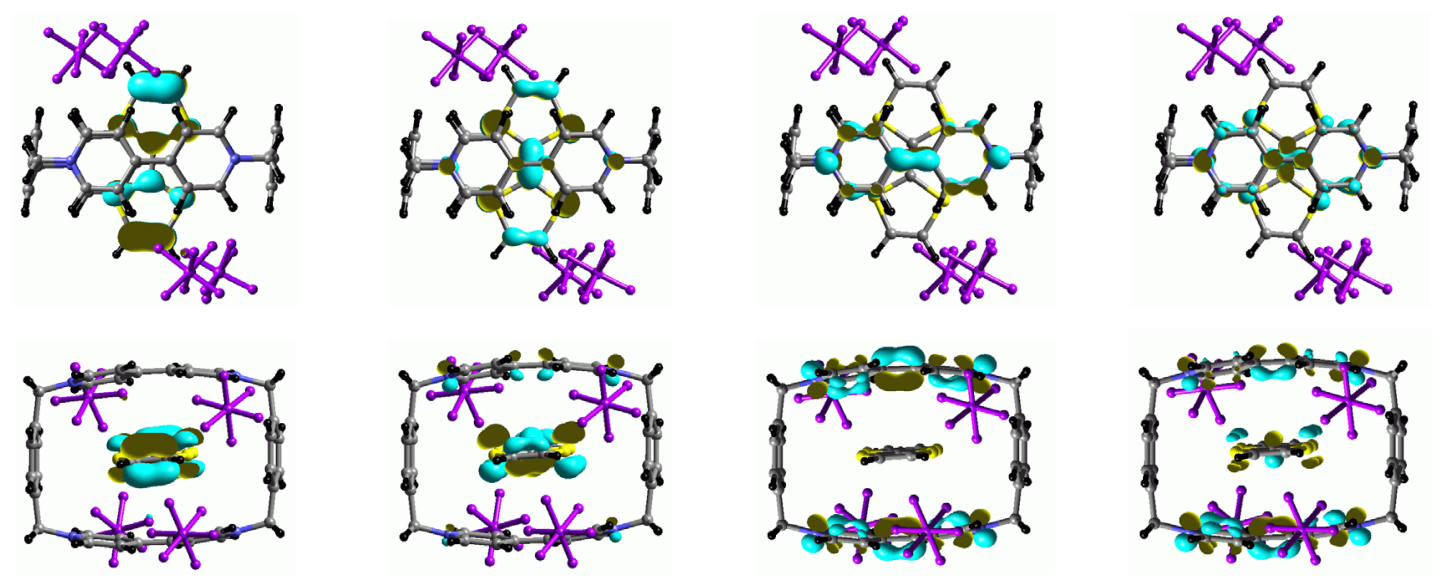

HOMO-1

HOMO

LUMO

$(-4.25 \mathrm{eV})$

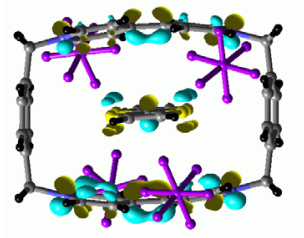

LUMO+1

$(-3.87 \mathrm{eV})$

Figure S6. FMO's of (TTF)(CBPQT) $\left(\mathrm{PF}_{6}\right)_{4}$. Color code: yellow $(\mathrm{S})$, blue $(\mathrm{N})$, gray $(\mathrm{C})$, black $(\mathrm{H})$, and purple $\left(\mathrm{PF}_{6}^{-}\right)$.
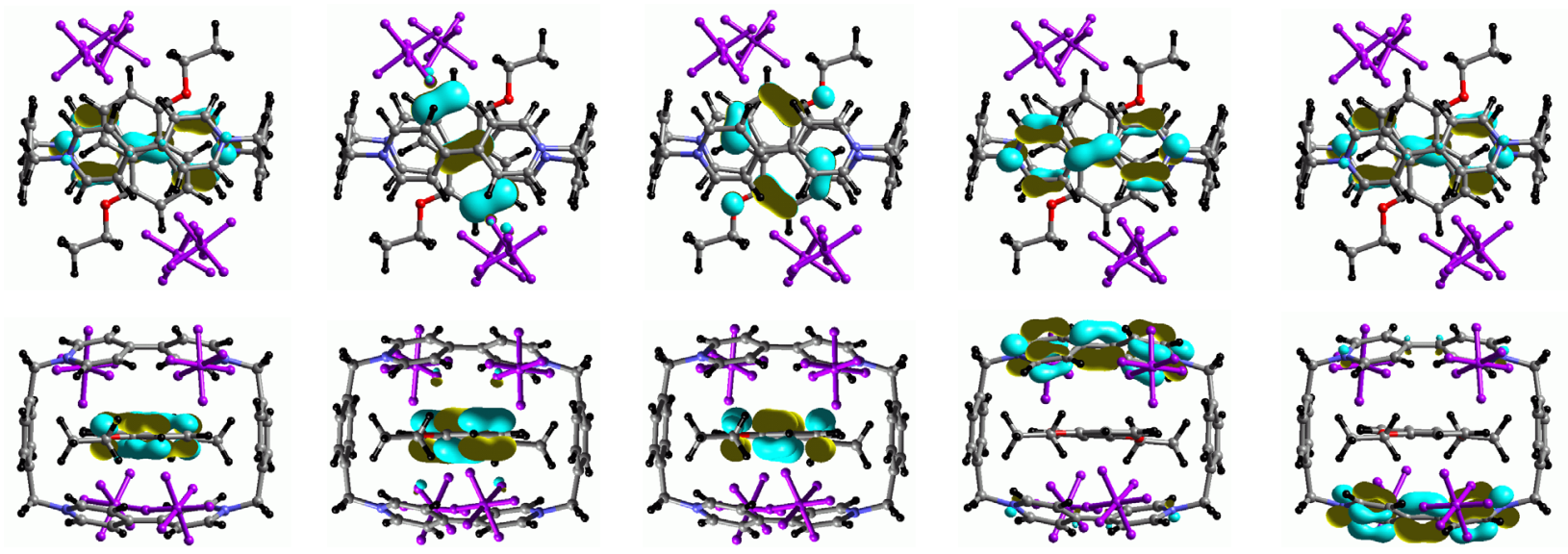

HOMO-2

HOMO-1

HOMO

LUMO

LUMO+1

$(-6.55 \mathrm{eV})$

$(-6.29 \mathrm{eV})$

$(-5.30 \mathrm{eV})$

$(-3.91 \mathrm{eV})$

$(-3.85 \mathrm{eV})$

Figure S7. FMO's of $(\mathrm{DNP})(\mathrm{CBPQT})\left(\mathrm{PF}_{6}\right)_{4}$. Color code: red $(\mathrm{O})$, blue $(\mathrm{N})$, gray $(\mathrm{C})$, black $(\mathrm{H})$, and purple $\left(\mathrm{PF}_{6}{ }^{-}\right)$. 

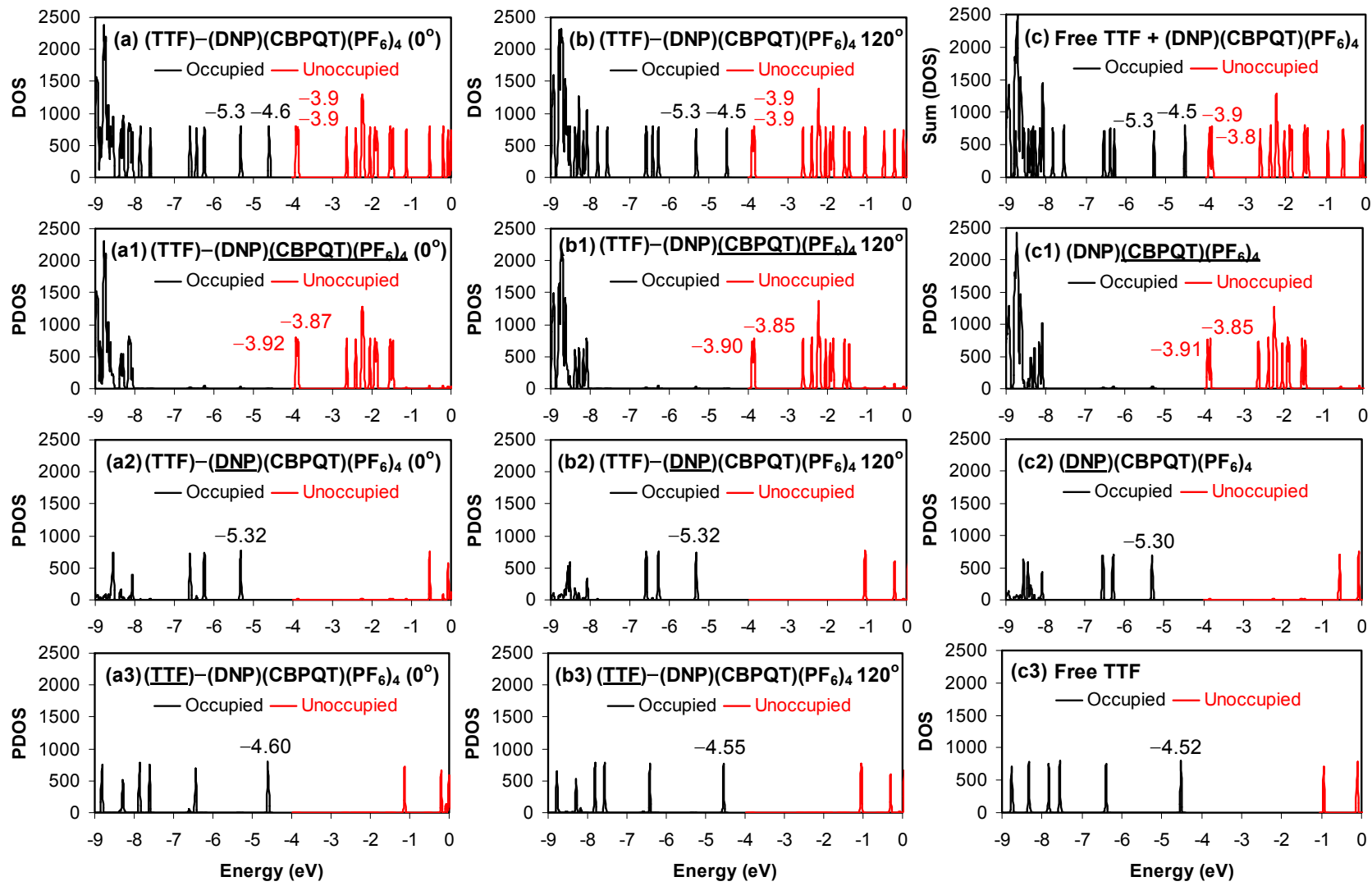

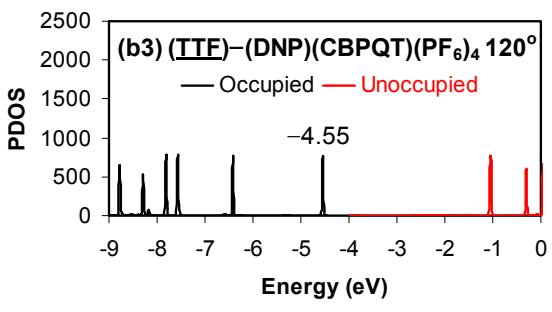

(b) Configuration 1A, twisted

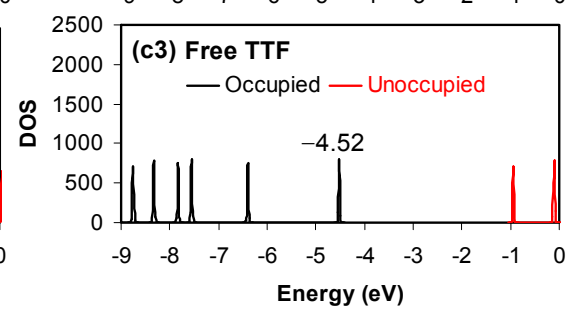

(c) Free TTF + (DNP) $(\mathrm{CBPQT})\left(\mathrm{PF}_{6}\right)_{4}$

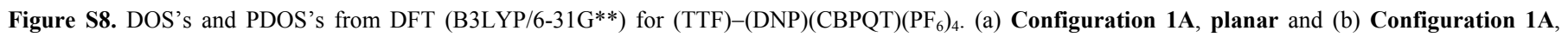

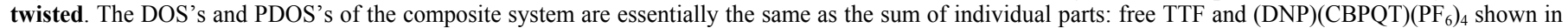
(c). 

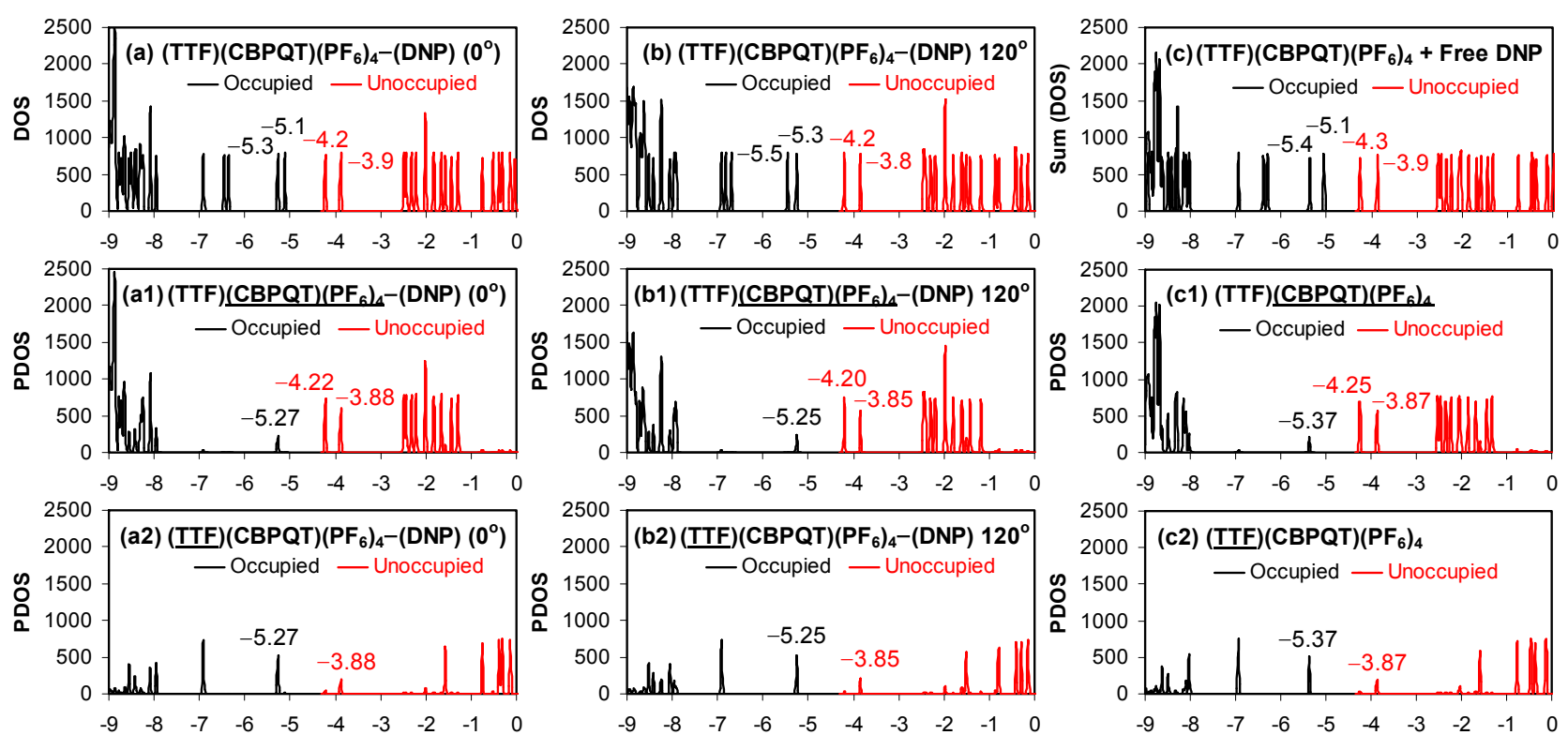

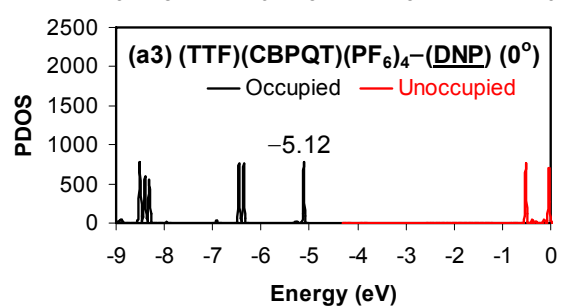

(a) Configuration 1, planar

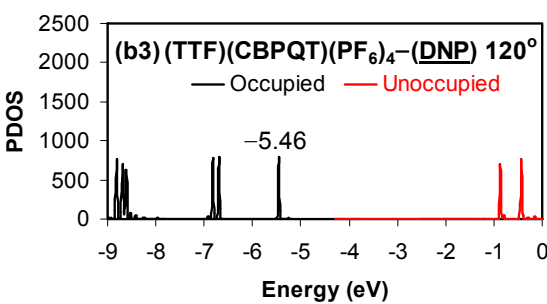

(b) Configuration 1, twisted

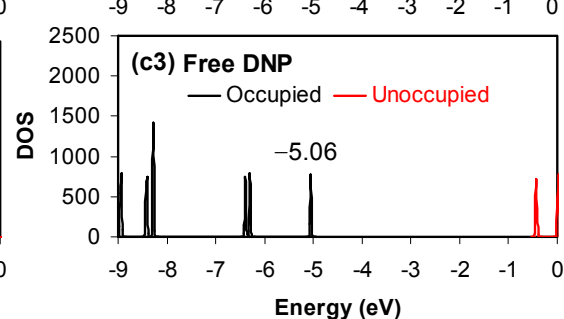

(c) $($ TTF $)\left(\right.$ CBPQT) $\left(\mathrm{PF}_{6}\right)_{4}+$ Free DNP

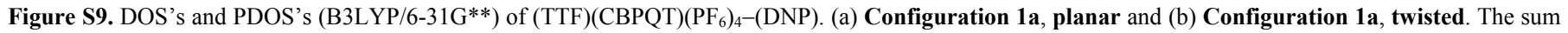
of DOS's and PDOS's of the individual parts, $(\mathrm{TTF})(\mathrm{CBPQT})\left(\mathrm{PF}_{6}\right)_{4}$ and free DNP, are shown together in $(\mathrm{c})$. 

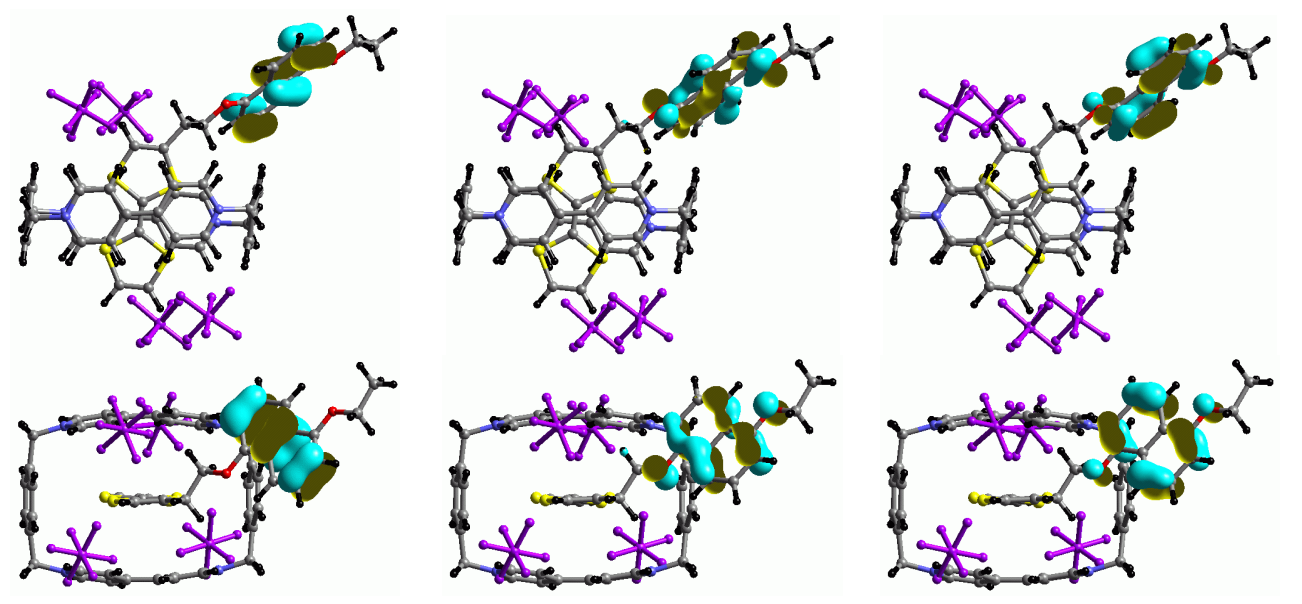

HOMO-3

HOMO-2

HOMO-1

$(-6.82 \mathrm{eV})$

(-6.69 eV)

$(-5.46 \mathrm{eV})$
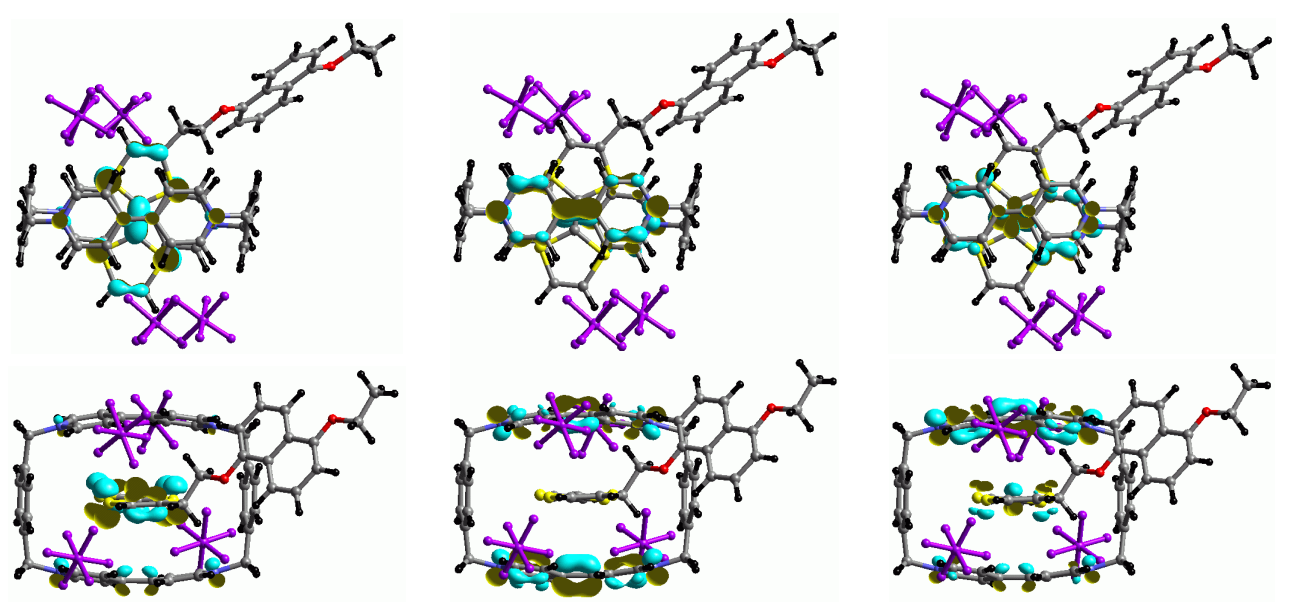

HOMO
$(-5.25 \mathrm{eV})$

LUMO
$(-4.20 \mathrm{eV})$

LUMO+1

$(-3.85 \mathrm{eV})$

Figure S10. FMO's of (TTF)(CBPQT) $\left(\mathrm{PF}_{6}\right)_{4}-(\mathrm{DNP})$ (Configuration 1a, twisted). Color code: yellow $(\mathrm{S})$, red $(\mathrm{O})$, blue $(\mathrm{N})$, gray $(\mathrm{C})$, black $(\mathrm{H})$, purple $\left(\mathrm{PF}_{6}{ }^{-}\right)$.

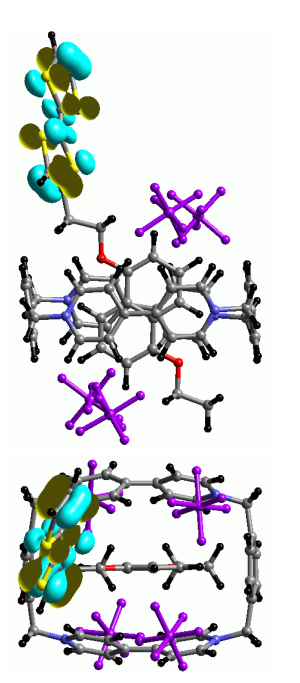

HOMO-3

$(-6.42 \mathrm{eV})$
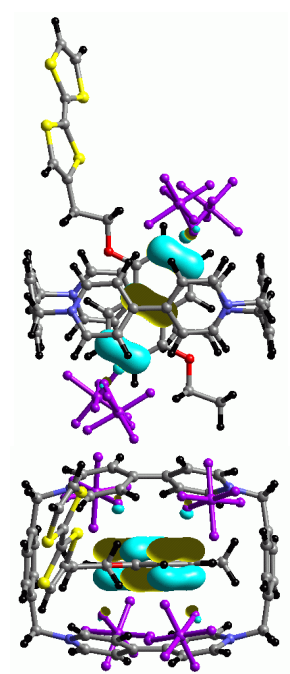

HOMO-2

$(-6.27 \mathrm{eV})$
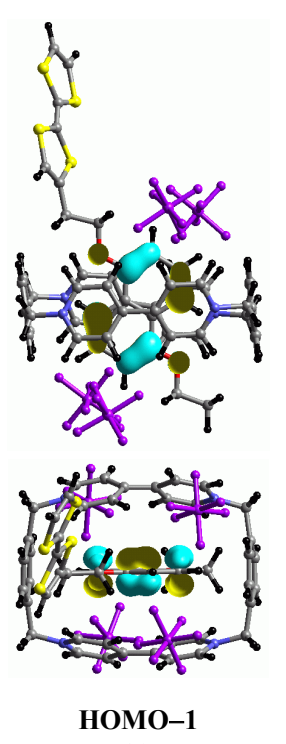

$(-5.32 \mathrm{eV})$
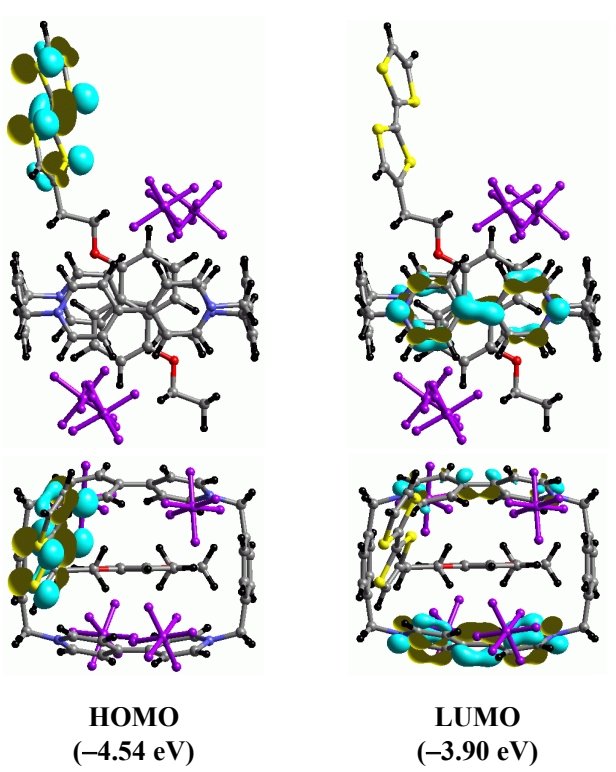

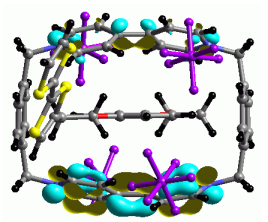

LUMO

$(-3.90 \mathrm{eV})$

Figure S11. FMO's of (TTF)-(DNP)(CBPQT) $\left(\mathrm{PF}_{6}\right)_{4}$ (Configuration 1A, twisted). Color code: yellow (S), red (O), blue (N), gray $(\mathrm{C})$, black $(\mathrm{H})$, purple $\left(\mathrm{PF}_{6}{ }^{-}\right)$. 


\section{B. PBE/6-31G**}
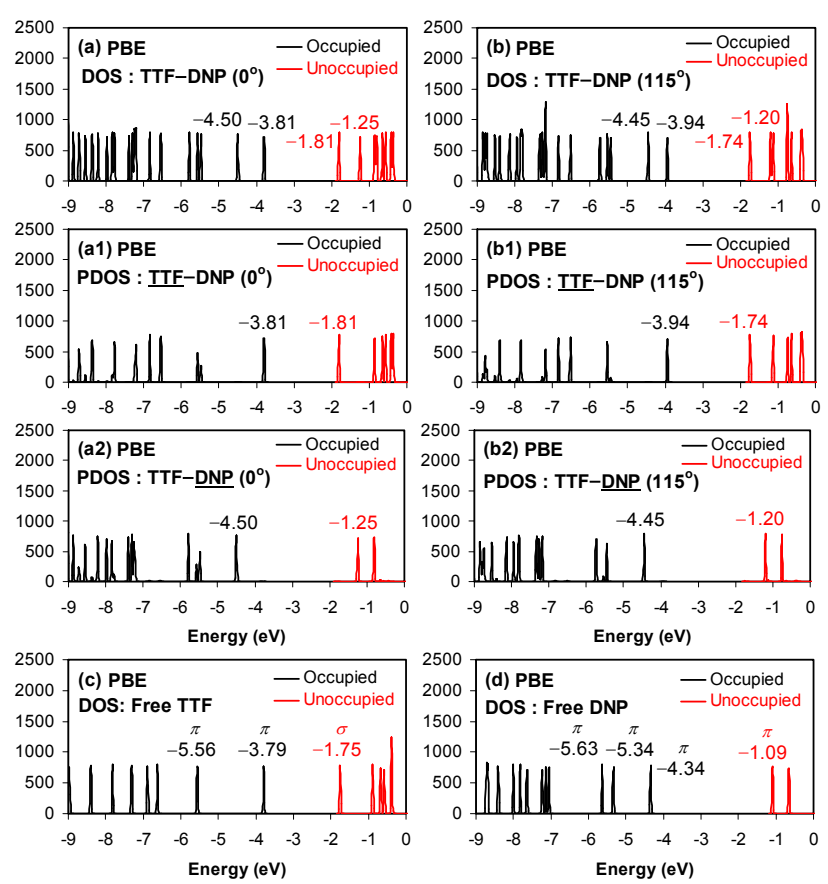

Figure S12. DOS's and PDOS's from PBE/6-31G** calculations of TTF-DNP for two different conformations (a) planar and (b) twisted. As in the B3LYP/6-31G** calculation, the states of each station, TTF and DNP, preserves its identity after the connection to each other, and the two conformations show essentially the same characteristics.
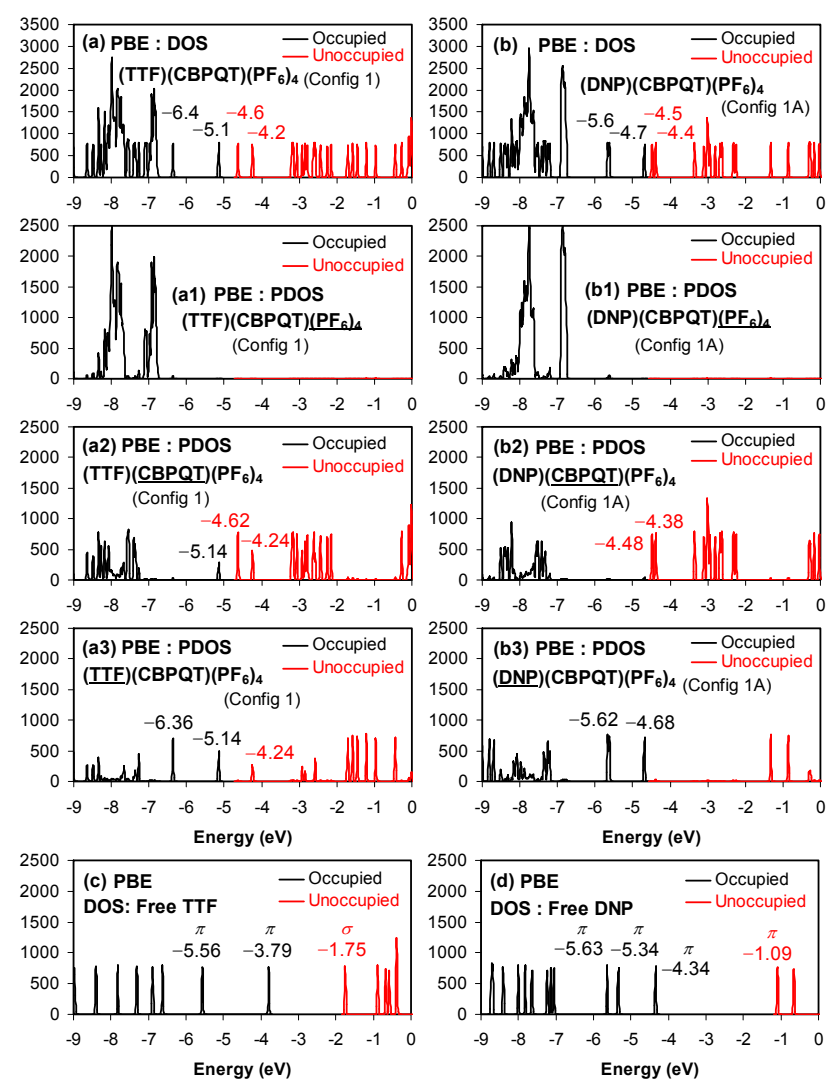

Figure S13. DOS's and PDOS's from PBE/6-31G** calculations of (a) $(\mathrm{TTF})(\mathrm{CBPQT})\left(\mathrm{PF}_{6}\right)_{4}$ and $(\mathrm{b})(\mathrm{DNP})(\mathrm{CBPQT})\left(\mathrm{PF}_{6}\right)_{4}$. This shows the effect of complex formation for $(\mathrm{a}, \mathrm{c}) \mathrm{TTF}$ and $(\mathrm{b}, \mathrm{d})$ DNP. As in the B3LYP calculations, complex formation lowers the energy levels of the frontier orbitals of both TTF and DNP, but in greater extent for TTF than for DNP. 

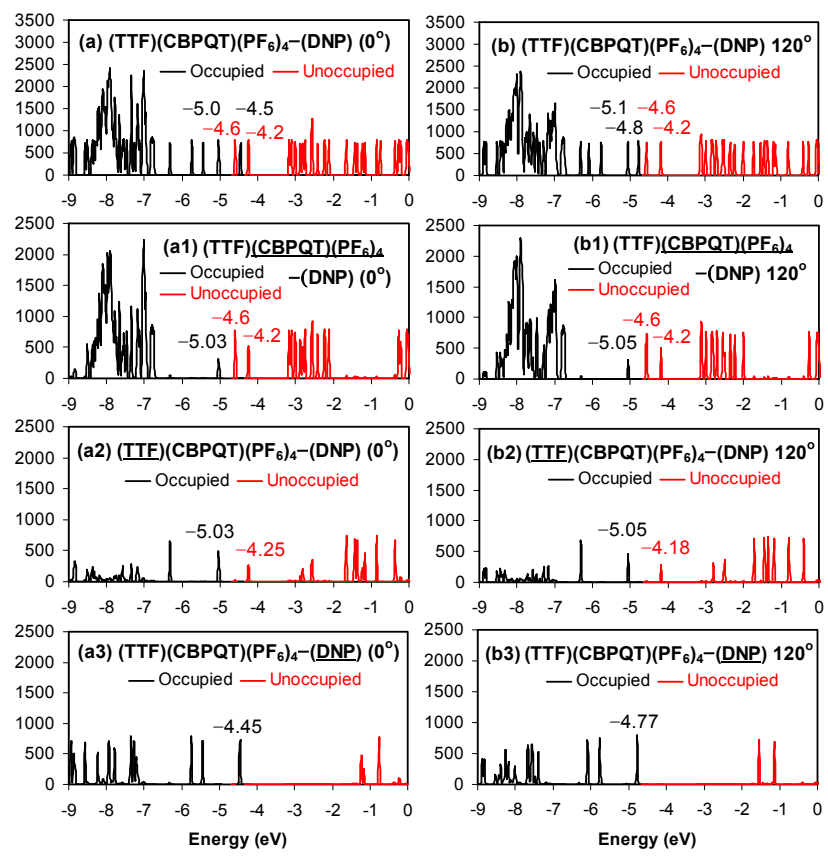

Figure S14. DOS's and PDOS's from $\mathrm{PBE} / 6-31 \mathrm{G}^{* *}$ calculations of (TTF) $(\mathrm{CBPQT})\left(\mathrm{PF}_{6}\right)_{4}-(\mathrm{DNP})$. (a) planar and (b) twisted.
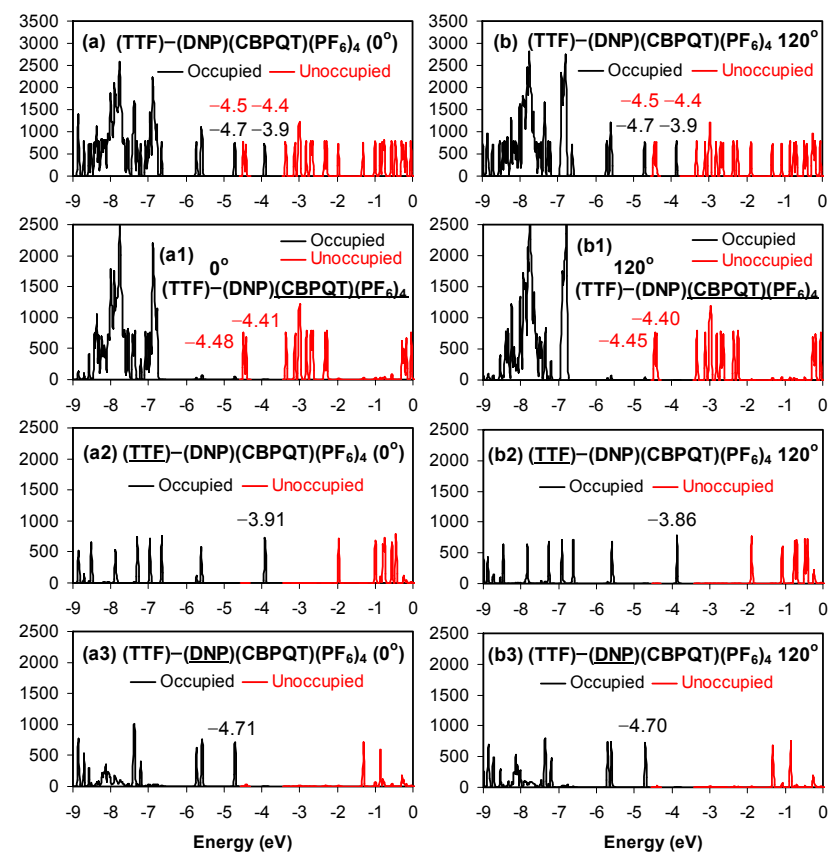

Figure S15. DOS's and PDOS's from PBE/6-31G** calculations of (TTF)-(DNP) $(\mathrm{CBPQT})\left(\mathrm{PF}_{6}\right)_{4}$. (a) planar and (b) twisted.
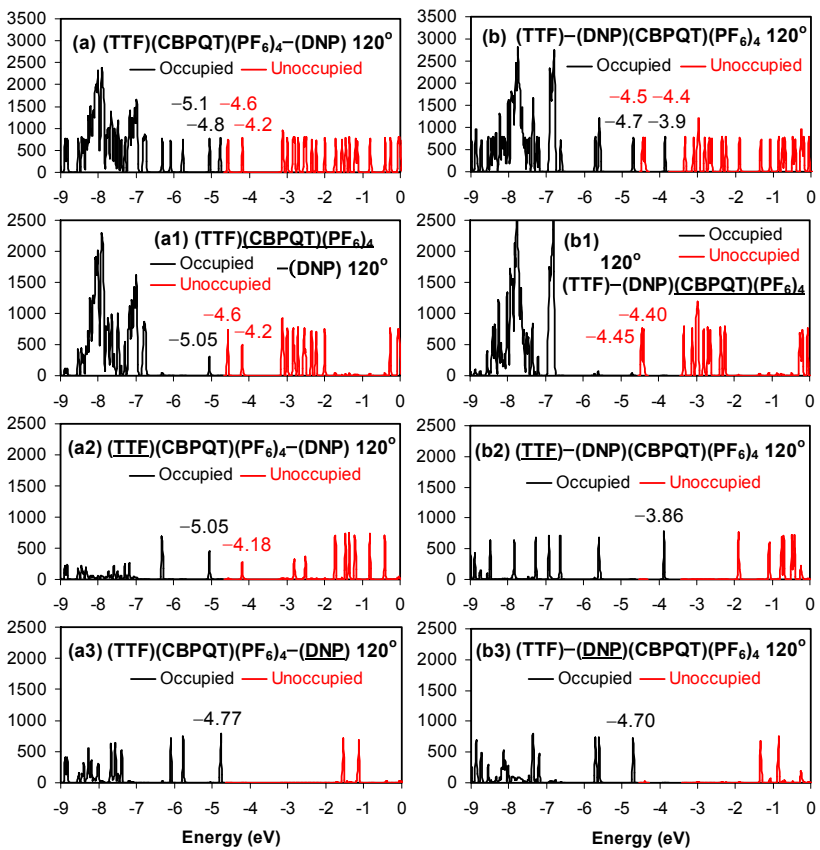

Figure S17. DOS's and PDOS's from PBE/6-31G** calculations on the twisted conformation of (a) (TTF)(CBPQT) $\left(\mathrm{PF}_{6}\right)_{4}-(\mathrm{DNP})$ and (b) (TTF)-(DNP)(CBPQT) $\left(\mathrm{PF}_{6}\right)_{4}$. 


\section{Alternative configurations}
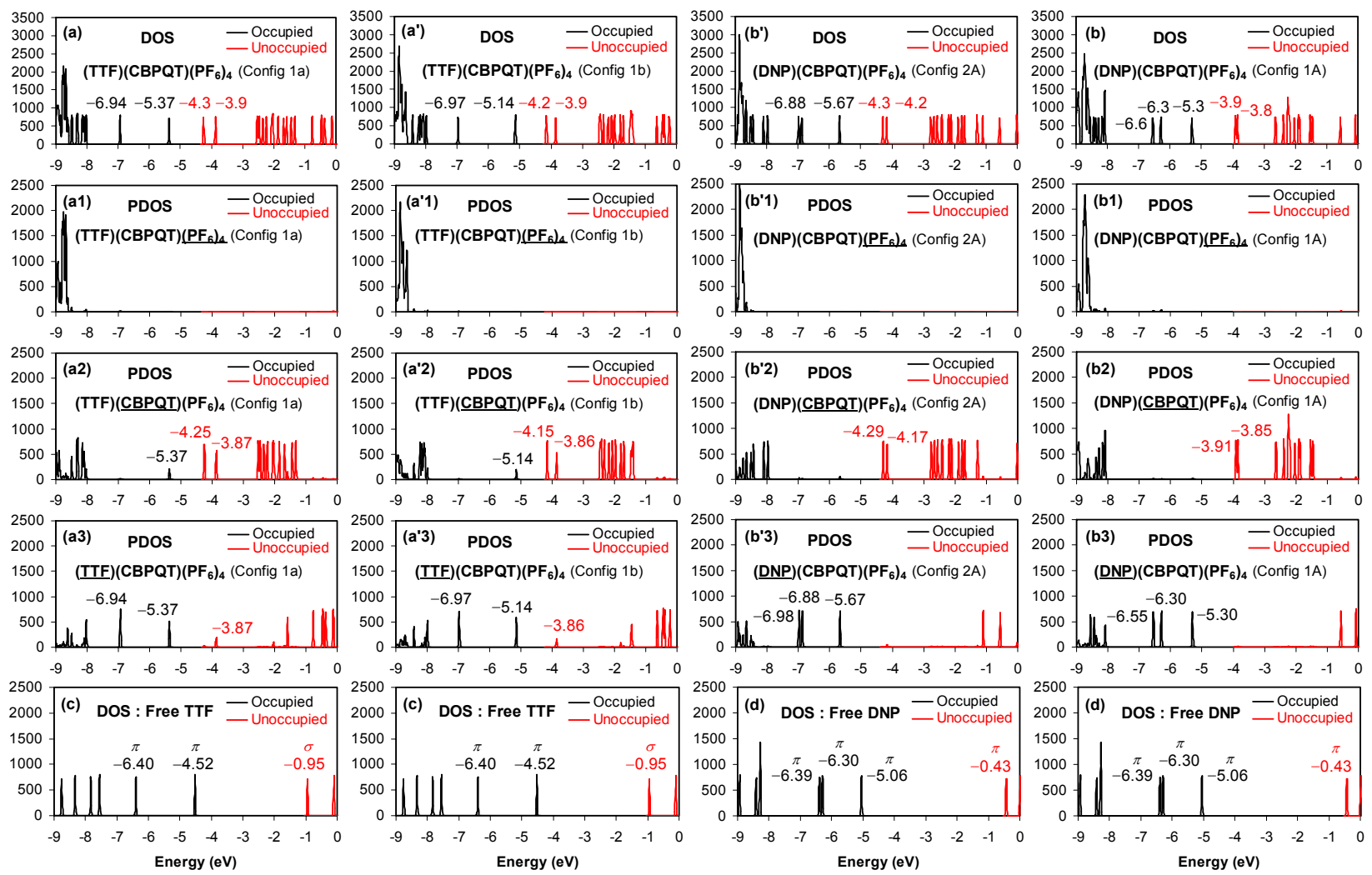

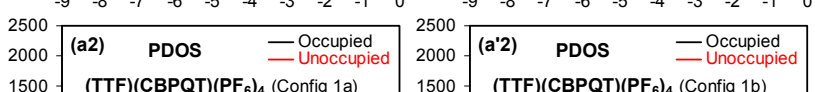
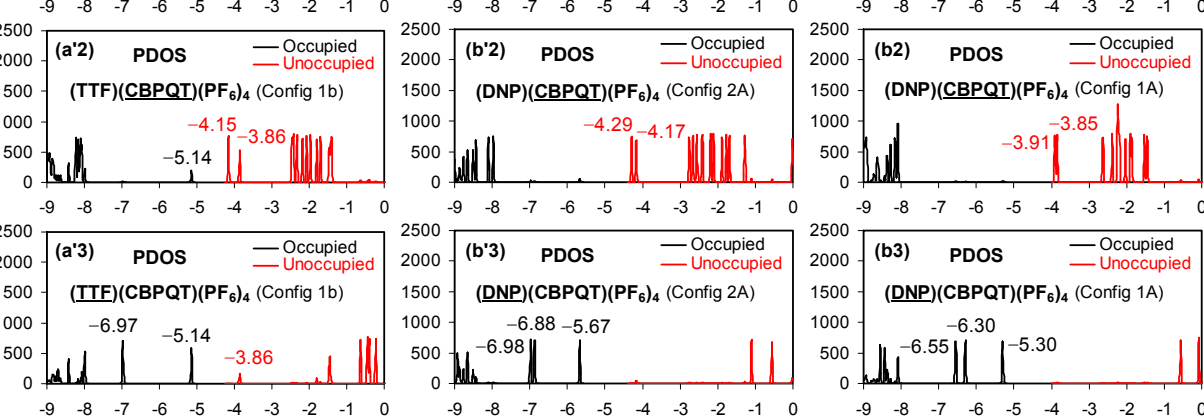

500

$-\left.5.14\right|^{-3.86}\||\|| \mid$

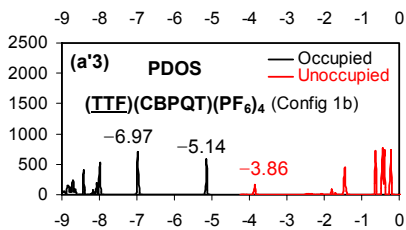

$\begin{array}{llllllllll}-9 & -8 & -7 & -6 & -5 & -4 & -3 & -2 & -1 & 0\end{array}$

2500 (b3) PDOS - Occupied

$1500-$ (DNP)(CBPQT) $\left(\mathrm{PF}_{6}\right)_{4}$ (Config 1A)

$1000--6.30$
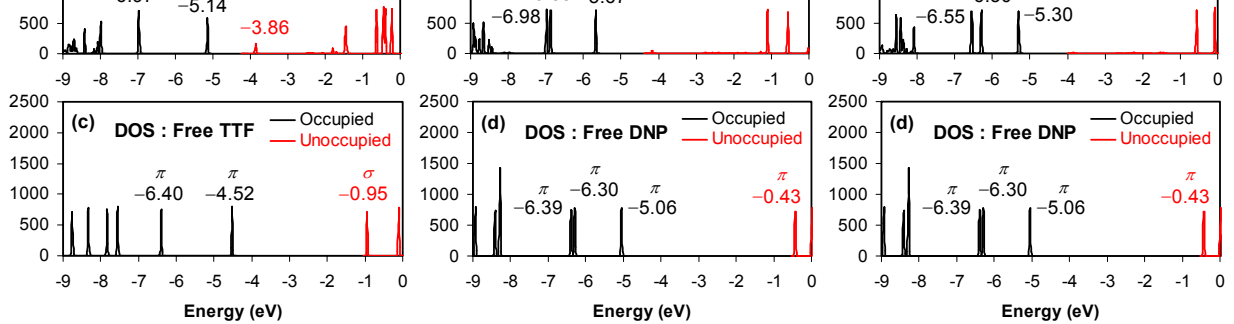

Figure S18. DOS and PDOS from B3LYP/6-31G** calculations for two different configurations of $(\mathrm{TTF})(\mathrm{CBPOT})\left(\mathrm{PF}_{6}\right)_{4}$ and $\left(\mathrm{DNP}^{2}\right)(\mathrm{CBPQT})(\mathrm{PF})_{6}$. (a) $(\mathrm{TTF})(\mathrm{CBPQT})\left(\mathrm{PF}_{6}\right)_{4}$ in Configuration 1a, $\left(\mathrm{a}^{\prime}\right)(\mathrm{TTF})(\mathrm{CBPQT})\left(\mathrm{PF}_{6}\right)_{4}$ in Configuration 1b, (b') $(\mathrm{DNP})(\mathrm{CBPQT})\left(\mathrm{PF}_{6}\right)_{4}$ in Configuration 2A, and $(\mathrm{b})$ $(\mathrm{DNP})(\mathrm{CBPQT})\left(\mathrm{PF}_{6}\right)_{4}$ in Configuration 1A. These figures include the PDOS of each fragment (TTF/DNP, CBPQT, and $\left.\mathrm{PF} 6\right)$ shown together. $(\mathrm{c}) \mathrm{DOS}$ of free TTF. (d) DOS of free DNP.

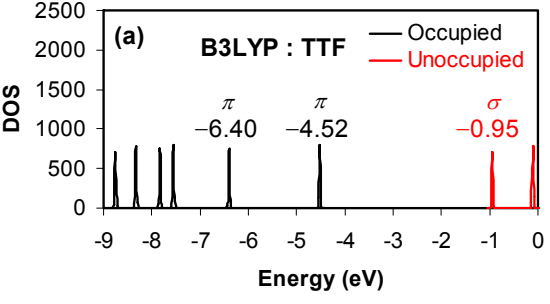

(a) Planar TTF

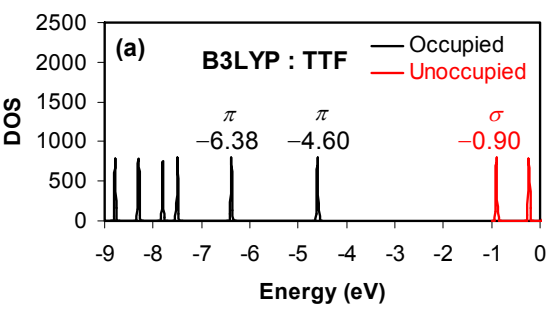

(b) Boat-shaped TTF

Figure S19. DOS from B3LYP/6-31G** calculations for two different minimum conformations of TTF. (a) Planar TTF and (b) boat-shaped TTF. The frontier orbital energy levels are very similar to each other, with the peak shifts less than $0.1 \mathrm{eV}$, which is much smaller than the shifts caused by forming a complex with $(\mathrm{CBPQT})\left(\mathrm{PF}_{6}\right)_{4}$. 